\title{
DECISION SUPPORT SOFTWARE AS A MEDIUM FOR TECHNOLOGY TRANSFER IN PLANT PROTECTION
}

\author{
M.R. LAURENSON ${ }^{1}$ and R.M. BERESFORD ${ }^{2}$ \\ The Horticulture and Food Research Institute of New Zealand Ltd., \\ ${ }^{1}$ Batchelar Research Centre, Private Bag 11030, Palmerston North \\ ${ }^{2}$ Mt Albert Research Centre, Private Bag 92169, Auckland
}

\begin{abstract}
Orchard 2000 software has been used to deliver weather-based plant disease models to horticultural users. Software for assessing the weather risk of apple black spot (Venturia inaequalis), developed, tested and commercialised over 6 years, gives users direct access to hourly weather data from 40 automatic stations in New Zealand's main horticultural regions. In the 1995-96 season, commercial users numbered 61, with a further 50 growers receiving twice weekly printouts via facsimile. A 1992 survey of 20 trial users indicated that use of the software did not reduce the number of fungicide applications, but typically led to the retiming of four applications. The survey also highlighted a need for knowledge of the persistence of protective fungicide cover. Spray diary software, also now commercialised, provides the first step towards such knowledge. In addition to being a planning and recording tool, the software offers a means of checking proposed spray applications for marketing compliance and mixing compatibility. Weather-based software for fire blight (Erwinia amylovora) and grape botrytis (Botrytis cinerea) are currently under development.
\end{abstract}

Keywords: decision support software, apple, technology transfer, Orchard 2000

\section{INTRODUCTION}

Several plant protection research programmes have achieved transfer of new pest and disease management technology through weather-dependent biological models delivered in either decision support computer software or on-orchard disease predictors. The Orchard 2000 system uses software on growers' personal computers (PCs) which links disease models with a weather database, as well as orchard and spray databases. The weather database is updated on demand from one or more of 40 electronic weather stations which are operated by HortResearch or independent operators. All stations measure air temperature, rainfall and surface wetness, and some measure a wider range of variables of World Meteorological Organisation standard. Although initial software has been developed for disease management applications, the Orchard 2000 system has the potential to incorporate any aspect of orchard management where weather information, biological models, or orchard layout detail are required.

This paper reviews the trial and commercialisation of a weather-based disease monitoring package based on the Orchard 2000 standard for decision support software (Laurenson et al. 1994). Orchard 2000, and its forerunner ODE, have been promoted as a mechanism for technology transfer and for validation of biological models (Laurenson 1989; Atkins et al. 1992). We examine the effectiveness of this medium in terms of:

- $\quad$ uptake - the proportion of potential users employing the medium

- $\quad$ use - the frequency with which they use the medium

- value - the value they place on the medium

- impact - the proportion of the total crop produced with the assistance of the medium

- $\quad$ science benefits - the medium's benefits to associated science programs

Proc. 49th N.Z. Plant Protection Conf. 1996: 85-89 
The costs of developing the current tools, and the marginal cost and pay back period of new applications are estimated, and grower priorities for new tools are explored.

\section{Uptake}

\section{RESULTS}

Laurenson and Manktelow (1992) reported field trials of Orchard 2000 software for monitoring apple black spot (Venturia inaequalis) involving two Nelson growers and several research sites. The software was trialed with 20 users in the 1992-93 season, and subsequently marketed as "Spot Check". There were 20 commercial users in 1993/94, 45 in 1994/95, and 62 in 1995/96.

Over this period nine clients have ceased using the software, some of these having left orcharding. In addition to commercial clients, the software is used by HortResearch staff, and 70 clients in the Hawkes Bay and Central Otago receive twice weekly faxes generated by the software. Table 1 shows the number of commercial software users in each of seven categories. Each of the corporate growers is managing at least five orchards.

\section{TABLE 1: Numbers of commercial users of Orchard 2000 software in seven categories of user type in 1995/96 season.}

User group No. of commercial users

$\begin{array}{lc}\text { Apple - corporate growers } & 4 \\ \text { Apple - other growers } & 38 \\ \text { Agrochemical retailers } & 8 \\ \text { Wine industry } & 4 \\ \text { Horticultural consultants } & 3 \\ \text { Cropping/vegetable farmers } & 4 \\ \text { Educational } & 1 \\ \text { TOTAL } & 62\end{array}$

\section{Use}

The version of Spot Check trialed in 1991/92 recorded the time and duration of usage. The two growers involved in the trial used the package 30 times over November and December, or once every 4 days on average.

\section{Value}

Orchard 2000 clients who only use the Spot Check package pay an installation fee of $\$ 200$, plus $\$ 200$ per year to run the software, and around $\$ 300$ per year for weather station access. In 1992, 20 trial users of the software in the Hawkes Bay were surveyed to review their use of the software. A similar survey was conducted in 1995. Of the 17 responses received in 1992, 15 ranked the main display of the software "very useful" and 2 ranked it "useful". The options "some use" and "useless" were not selected by respondents. Users also found a table summarising daily weather to be useful, with 15 ranking this information either "useful" or "very useful".

Users were asked how many times the software had changed the way they had applied fungicide. In 1992, a particularly wet spring, users said that on average there were two occasions when the software convinced them that they should spray when they otherwise would not have, and two occasions when the converse applied. Growers in the 1995 survey said that there was one occasion in each category. The standard error in both responses in both surveys was about one occasion. Beresford $e t$ al. (1989) have identified that in regions or seasons where black spot infection periods occur at less than approximately 10 day intervals, there is little scope to reduce numbers of applications using weather information. There is still, however, scope to improve the timing of applications through infection period monitoring.

In 1992, in response to the question "To what extent do you believe that Spot Check represents the weather risk of infections during the black spot season?", 15 of 
the 17 respondents selected "...most of the time". One respondent chose "...all of the time". This indicated that respondents took the information from the monitor and combined it with other information in making decisions.

In 1995, in response to the question "Do you think Spot Check improved your black spot control?", 13 respondents answered "Yes", and four answered "No". In response to the question "Did the use of Spot Check reduce any uncertainty you may have had associated with black spot control?", 16 of the 17 respondents answered "Yes" and one answered "No".

\section{Impact}

We do not have an accurate figure for the total acreage of apple trees grown by users of the software, but three of the corporate clients between them grow about $10 \%$ of New Zealand's 13,000 ha of apples (Statistics New Zealand, 1995). Assuming that the 70 clients of the Faxout service have average size orchards (10 ha), these growers would account for a further 5\% of the crop area. The Hawkes Bay has $40 \%$ of New Zealand's planted apple area (Statistics New Zealand, 1995). The three major agrochemical retailers in the Hawkes Bay use the software and "often" refer to it when discussing disease management with their clients, and their representatives are the most important source of pest and disease management information for $68 \%$ of growers (Stewart et al. 1993). Therefore, it is likely that much of the Hawkes Bay apple production is at least indirectly influenced by the software.

\section{Science benefits}

A Windows Dynamic Linked Library (DLL) has been developed which allows weather data in spreadsheets to be automatically updated when, for example, a single date in the spreadsheet is changed. This has allowed simple weather-driven models to be developed, validated, and distributed using the spreadsheet medium. Weatherdriven disease monitors compatible with Orchard 2000 are under development for fire blight (Erwinia amylovora) and grape botrytis (Botrytis cinerea). DOS-based versions of both products working from the Orchard 2000 weather database have assisted in the validation of weather-driven models and have already been trialed by some growers.

\section{Costs and revenue}

Government investment in the Orchard 2000 system to date (through the Public Good Science Fund) totals around $\$ 1$ million, excluding investment in the associated biological science. A further $\$ 50,000$ from the parent organisation (HortResearch) has been invested in converting science prototypes into distributable commercial products. Of this investment, approximately $\$ 500,000$ relates to the tools now available to growers, or about $\$ 100,000$ per tool. Improvements in software development tools, and the library of software routines that have been developed, mean that the marginal cost of developing, testing and documenting a new weather-based tool is around $\$ 15,000$. This assumes that the underlying science is sufficiently well developed that further validation of the underlying model need not take place.

Software licence fees (excluding weather station fees) in the latest season of commercial operation total about $\$ 30,000$, or $\$ 6000$ per tool. Approximately two thirds of this income is consumed in sales commissions, and support costs, leaving a net revenue of around $\$ 2,000$ per tool. On this basis it is possible for the technology process to be self-funding with a pay back period of around 12 years at $8 \%$ annual interest. Increasing the number of users would shorten the pay back period.

\section{Priorities for software development}

Users were asked to allocate notional resources $(\$ 100)$ to six proposed improvements to Spot Check and to allocate a further $\$ 100$ to 11 possible new Orchard 2000 modules. Responses are summarised according to relative popularity (number of respondents who allocated any money to the option) and importance (average amount allocated to an option when amount allocated is greater than zero) in Table 2.

The results indicate strong interest in an electronic spray diary linked to disease management software. In response to this survey, a spray diary has been developed and commercialised, and links between this and Spot Check are being developed. A growing degree calculator and general weather viewer have also been developed and commercialised. 
TABLE 2: Results of the 1992 survey of nine Hawkes Bay growers showing popularity and importance ranking for additions to "Spot Check" black spot management software, and new packages.

\begin{tabular}{lrrr}
\hline Additions to "Spot Check" & $\begin{array}{r}\text { Popularity } \\
(\%)\end{array}$ & $\begin{array}{r}\text { Importance } \\
\text { (average \$) }\end{array}$ & $\begin{array}{r}\text { Total } \\
(\$)\end{array}$ \\
\hline Display fungicide applications (cover duration) & 100 & 53 & 481 \\
Report regional ascospore release measurements & 89 & 26 & 210 \\
Make additional weather elements available & 67 & 22 & 126 \\
Expert assessment of black spot weather risk & 67 & 10 & 60 \\
Improve documentation & 33 & 4 & 13 \\
Improve weather station downloading process & 11 & 10 & 10 \\
TOTAL & & & 900 \\
& & & \\
New modules & 100 & 22 & 200 \\
Electronic spray diary & 88 & 16 & 131 \\
Fruit size tracking & 67 & 21 & 127 \\
Forecast maps, text and/or satellite pictures & 77 & 13 & 89 \\
Growing degree accumulator & 77 & 12 & 86 \\
Fire blight monitor & 67 & 14 & 83 \\
Better access to weather data & 56 & 13 & 63 \\
Gross margin analyser (block profitability) & 44 & 13 & 50 \\
European red mite phenology predictor & 44 & 11 & 43 \\
Frosts & 33 & 8 & 25 \\
Nutrition model & 11 & 3 & 3 \\
Chemical thinning assistance (whether \& when) & & & 900 \\
TOTAL & &
\end{tabular}

A similar survey of 17 grower users was undertaken in 1995, after development had commenced on the spray diary and other packages. This survey, with a single category "Enhancements", yielded the preferences (in descending order of total "dollars" allocated) shown in Table 3.

TABLE 3: Results of the 1995 survey of 17 Hawkes Bay growers showing popularity and importance ranking for proposed enhancements to "Spot Check" black spot management software.

\begin{tabular}{lccr}
\hline Enhancements & $\begin{array}{c}\text { Popularity } \\
(\%)\end{array}$ & $\begin{array}{c}\text { Importance } \\
\text { (relative \$) }\end{array}$ & $\begin{array}{r}\text { Total } \\
(\$)\end{array}$ \\
\hline Forecast maps, text and/or satellite pictures & 56 & 32 & 318 \\
Regional ascospore release measurements & 67 & 21 & 257 \\
Historical data in growing degree calculator & 72 & 14 & 175 \\
European red mite phenology predictor & 56 & 15 & 152 \\
Fruit size tracking/revenue forecasting & 50 & 16 & 148 \\
Expert assessment of black spot weather risk & 33 & 22 & 134 \\
Fire blight monitor - Windows version & 56 & 12 & 117 \\
Chemical thinning assistance (whether \& when) & 44 & 14 & 112 \\
Better summaries \& graphs of weather data & 22 & 19 & 77 \\
Additional weather elements & 33 & 12 & 74 \\
Nutrition model & 22 & 17 & 66 \\
Frost monitoring (10 min. readings if temp $\left.<2^{\circ} \mathrm{C}\right)$ & 17 & 13 & 38 \\
"Safety checks" in spray diary & 17 & 11 & 32 \\
Replanting decisions aids & 0 & & 0 \\
TOTAL & & & 1700 \\
\hline
\end{tabular}


Regional ascospore measurements for $V$. inaequalis were of high priority in both surveys, as was weather forecast information. A test version of a DOS-base fire blight monitor was issued to some growers between the surveys and this may explain the lower ranking of this option in the later survey. Low scores were given to nutrition advice and frost warnings in both surveys.

Both surveys were of relatively small groups of users. Nevertheless the results were quite consistent between surveys and give an indication of industry priorities for further development of Orchard 2000 tools.

\section{CONCLUSION}

Decision support software represents a relatively expensive, but effective medium for technology transfer of plant protection science. Direct adoption appears to have been low in terms of the number of growers, but we believe the system is having a considerable indirect influence on black spot decision making. Tools for rapidly developing such software, particularly using weather-based models, are now available.

\section{ACKNOWLEDGEMENTS}

This research was funded by the New Zealand Foundation for Research, Science, and Technology, and The Agricultural and Marketing Research and Development Trust.

\section{REFERENCES}

Atkins, T.A., Laurenson, M.R., Mills, T.M. and Ogilvie, D.K., 1992. Orchard 2000: Towards a decision support system for New Zealand's orchard industries. Acta Hort. 313: 173-182.

Beresford, R.M., Salinger, M.J., Bruce, P.E. and Brook, P.J., 1989. Frequency of infection periods for Venturia inaequalis in New Zealand and implications for fungicide use. Proc. 42nd N.Z. Weed and Pest Control Conf.: 159-164.

Laurenson, M.R., 1989. ODE - Orchard Decision Environment. Acta Hort. 276: 301304.

Laurenson, M.R., Buwalda, J.G. and Walker, J.T.S., 1994. Orchard 2000 - a decision support system for New Zealand's orchard industries. N.Z. J. Crop Hort. Sci. 22: 239-250.

Laurenson, M. and Manktelow, D., 1992. Monitor: A computer-based tool for monitoring Black Spot infection periods. Acta Hort. 313: 197-204.

Statistics New Zealand 1995. Agriculture Statistics 1993. August 1995, Wellington.

Stewart, T.M., Norton, G.A., Mumford, J.D. and Fenemore, P.G., 1993. Pest and disease decision support for Hawkes Bay apple growers - a survey.Proc. 46th N.Z. Plant Prot. Conf: 152-161. 